\title{
The Profile of Task Performances for Cognitive-communicative Intervention in the Oldest-Old
}

\author{
Mi Sook Lee ${ }^{1,2}$ \\ ${ }^{1}$ Department of Audiology \& Speech-Language Pathology, Hallym University of Graduate Studies, Seoul, Korea \\ ${ }^{2}$ HUGS Center for Hearing and Speech Research, Hallym University of Graduate Studies, Seoul, Korea
}

\author{
Received: April 29, 2021 \\ Revised: May 31, 2021 \\ Accepted: June 2, 2021 \\ Correspondence: \\ Mi Sook Lee, PhD \\ Department of Audiology \& Speech- \\ Language Pathology, Hallym \\ University of Graduate Studies, 427 \\ Yeoksam-ro, Gangnam-gu, Seoul \\ 06197, Korea \\ Tel: $+82-70-8680-6961$ \\ Fax: $+82-2-3453-6618$ \\ E-mail: mslee2018@hallym.ac.kr
}

\begin{abstract}
Purpose: The "oldest-old" is the heterogeneous population compared with the younger-old in several cognitive-communication aspects. Accordingly, it is necessary to intervene in them discriminately. This study aimed to suggest the performance profiles by cognitive-communication tasks for intervention in oldest-old. Methods: Sixty-four oldest-old subjects aged 80 or older years performed 16 subtasks for the five cognitive-communication domains. And the performance profiles of group I ( $84.00 \pm 2.62$ years) and II (93.38 \pm 1.61 years) were analyzed. Results: The main findings were as follows. Firstly, two groups had significant differences in performances of most tasks including working memory, reasoning, word fluency, and subjective communication. Secondly, five communication tasks were significantly correlated with all cognitive tasks and were predicted by the reasoning tasks like similarity in group I. Thirdly, word fluency and pragmatic expression tasks were significantly correlated with all cognitive tasks. Tasks including verbal problem solving were found to be the best predictors of confrontation naming in group II. Conclusion: Current study provides evidence-based information to support cognitive-communication intervention for the oldest-old. These results also can contribute to increase the efficacy of the cognitive-communicative intervention.
\end{abstract}

Key Words: Oldest-old, Cognitive-communication, Performance profiles, Intervention.

\section{INTRODUCTION}

전 세계적인 고령화 추세로 인해 80세 이상의 초고령층 (oldest-old) 인구가 급증하고 있다(Lee, 2021). 초고령층의 정 의는 기준이나 연구 목적에 따라 다양한데, 사회 구성원 중 매 우 높은 연령대를 통칭하며 보편적으로 80세 이상 노인 인구를 의미한다. 초고령층은 다양한 유형의 신경병리학적 문제를 수반 하는데, 이는 인지-의사소통의 수행력과 연계된다(Montine et al., 2019). 또 치매 증상 이외의 병리적 양상, 즉 감각 결함, 심리 사회적 고립 등이 동반될 가능성도 높다. 따라서 초고령층은 연 소 노인층(younger-old)의 속성과 이질적이며 중재 시 변별적 인 접근이 요구된다.

이 같은 특수성을 고려할 때 초고령층 대상의 인지-의사소통 중재 시 활용할 수 있는 과제별 수행 프로파일이 제시될 필요가

(c) This is an Open Access article distributed under the terms of the Creative Commons Attribution Non-Commercial License (https://creativecommons.org/ licenses/by-nc/4.0) which permits unrestricted non-commercial use, distribution, and reproduction in any medium, provided the original work is properly cited.
있다(Miller et al., 2010). 이와 관련된 주요 고려점은 다음과 같 다. 첫째, 연령은 알츠하이머형 치매(Alzheimer's disease, AD) 등을 유발하는 강력한 위험인자이다(Lee, 2021). 그러므로 초 고령층은 치매에 가장 취약한 집단으로, 이들에 대한 인지-의사 소통 프로파일의 임상적 활용도가 매우 높다.

둘째, 초고령층의 노화 양상은 매우 변이적이고 이질적이 다. 노화와 인지-의사소통의 상관성에 관한 모델에 따르면, 새 로운 상황에 효율적으로 적응하는 데 활용되는 유동성 지능 (fluid intelligence)은 고령층일수록 저하되는 반면, 언어나 사 전 지식을 기반으로 친숙한 과제를 수행하기 위한 결정성 지능 (crystallized intelligence)은 연령효과가 적다(Verhaeghen, 2011). 또 지적 구조의 변화는 대체로 완만한 하향 곡선을 띤다 는 견해가 보편적이나, 개인의 발달 곡선 내에서 통합적으로 간 주되어야 한다는 주장도 있다(MacDonald et al., 2011). '인지 적 노화의 전두엽 가설은 연령에 따라 전두엽의 기능 저하가 뚜 렷하다는 이론이지만, 전두엽 내에서도 연령의 영향을 받는 영역 과 그렇지 않은 영역이 공존한다는 지적도 있다(MacPherson 
et al., 2002). 궁극적으로 초고령층의 인지-의사소통 프로파일 이 노화의 경로를 순차적으로 따를 수도 있고 안정기(plateau) 나 유연성(resilience), 개인 차이가 작용하기도 한다(Miller et al., 2010). 실제로 70대 노인층에 비해 초고령층의 인지-의사소 통 수행이 전반적으로 낮고 급속도로 저하된다는 보고가 있는 반 면(Hagberg et al., 2001), 연구 설계의 한계로 인해 보편화된 프로파일을 제시하기 어렵다는 견해도 있다(Poon et al., 2007).

셋째, 정상 노화, 고령층, 초고령층 간을 변별하는 명확하고 신 뢰할 만한 인지-의사소통 프로파일이 부족한 실정이다. 이는 인 지-의사소통의 영역 및 과제별 수행 양상이 연령에 따라 다양하 고 상호 연계적인 속성이 관여하기 때문이다. 예컨대, 주의력, 작 업기억, 화용적 추론, 집행기능 등의 인지 영역과 상관성이 높은 비유언어 이해는 노인의 연령에 따라 차이가 있다. 65 74세의 연소 노인은 속담과 이름대기, 비유와 분리주의력, 비유와 집행 기능 간 그리고 75 84세의 중고령 노인은 속담과 집행기능, 비 유와 단어유창성, 관용구와 단어유창성이 상관성을 갖는다. 또 85세 이상의 초고령 노인은 분리주의력과 속담 이해 간의 상관 성이 높다(Lee \& Kim, 2018).

초고령층의 인지-의사소통 중재를 위한 수행 프로파일은 각 하위 영역이나 과제 유형별로 논의될 수 있다. 인지 측면에서 나 타나는 초고령층의 수행 양상은 기억력, 특히 작업기억 과제 를 통해 살펴본 연구들이 많다. 예컨대, 연령효과가 보편적으로 규명된 인지 영역은 처리 속도(Wahl et al., 2010), 억제(ReyMermet \& Gade, 2018), 전환 처리(Wasylyshyn et al., 2011), 작업기억(Klencklen et al., 2017) 등이다. 이들은 계획화, 추 론, 문제해결, 읽기 이해 등 일상생활의 인지-의사소통 수행에 필 수적이다(Thompson et al., 2013). 특히 구어뿐 아니라 비구어 작업기억 용량은 문장 이해와 상관성이 높다. 따라서 작업기억과 집행기능의 저하를 예방하는 것은 초고령층의 중재에 매우 효과 적일 수 있다. 특히 작업기억은 전반적인 인지-의사소통 수행과 고차원적 인지활동의 핵심 영역으로서 초고령층 중재의 주요 목 표를 이룬다(Matysiak et al., 2019). 실제로 작업기억은 단순한 주의력부터 고차원적 인지-언어 과제까지 다양한 수행의 결정적 지표로 꼽힌다(Fukuda \& Vogel, 2009). 이로 인해 작업기억 과 제에 기반한 훈련의 효과성을 높임으로써 인지-의사소통 수행의 다층적 향상을 기대할 수 있다.

초고령층의 인지 수행 중 고차원적 인지는 연령 특화적인 양 상이 뚜렷한 영역에 해당한다. 추론력, 문제해결력, 집행기능 등 의 고차원적 인지가 초고령층에게 매우 취약한 영역이기 때문 이다. 추론 과제의 난이도가 높을수록 인지 처리 속도가 떨어지 므로 수행에 어려움을 가중시킨다(Salthouse, 2000). 문제해결 력은 노화 단계에서 변별력이 높은 또 다른 영역으로, 맥락적 특 성, 특정 상황의 요구, 문제의 발생 공간, 감정적 제어, 사고 과정,
처리 속도, 회피-거부 전략, 친숙도 등이 변수가 된다(Burton et al., 2009). 집행기능은 목표 중심적 및 미래 지향적 행동뿐 아 니라 단순한 인지활동의 조절과 억제에 관여하는 일련의 과정이 다. 노화는 자유의지, 계획화, 목표 지향적 행동, 효과적 수행에 기반한 집행기능의 수행에 부정적인 영향을 미치는데, 이는 주의 력, 작업기억, 인지적 유연성, 의사결정, 판단, 행동 억제와 연관 된다(Bakos et al., 2008). 다만 고령층과 초고령층 간의 차이는 교육연수, 인지적 가소성(cognitive plasticity), 집행기능의 하 위 영역 등에 따라 다를 수 있다. 예컨대, 의사결정이나 학습 과 정에 관여된 집행기능 과제에서 초고령층의 저하가 두드러진다 (Bakos et al., 2008).

초고령층의 의사소통 수행은 인지 양상과의 상관성이 높고 일 상의 기능적 측면을 반영한다는 점에서 매우 중요하다. 특히 언 어의 어휘-의미적 양상은 연령 효과가 매우 뚜렷하다고 알려져 있다. 초고령층의 작업기억, 주의력, 집행기능, 처리 속도 등의 결 함과 사회적 활동의 감소는 의사소통기능을 방해한다. 즉 인지사회적 요구가 감소하면 어휘-의미적 접근이 어려우며 맥락에 맞 는 언어 표현이 저하된다(Keller-Cohen et al., 2006). 예를 들 어, '노인 언어(elderspeak)'라 일컫는 노년층의 언어 양상은 메 시지를 전달하고 이해하는 데 어려움을 주므로 의사소통기능 을 크게 저해한다. 이름대기 과제도 연령 효과가 가장 두드러지 는 영역 중 하나이다(Maseda et al., 2014). 초고령층의 자발 화에 빈번한 설단(tip-of-the-tongue) 현상, 단어유창성(word fluency)의 저하도 어휘-의미적 차원의 결함에 해당한다(Lee, 2021). 특히 초고령층은 의미적 유창성 과제를 수행할 때 관련 영역을 선택적으로 활성화하거나 불필요한 부분을 억제하는 능 력이 떨어진다(Peach \& Shapiro, 2020).

초고령층의 의사소통 프로파일에서 화용적 측면이 차지하는 중요성은 매우 크다. 화용언어는 청각적 정보의 이해 및 처리 속 도, 작업기억, 집행기능 등과 연계되어 초고령층의 속성을 민감 하게 반영하기 때문이다. 담화의 경우 언어의 의미와 구문, 화용 측면을 통합적으로 반영하므로 작업기억에 크게 의존한다. 초 고령층의 제한적인 작업기억 용량은 적절한 정보 전달과 효율적 인 의사소통을 방해한다(Lee \& Kim, 2020). 이 같은 양상은 75세를 기점으로 연령이 높아질수록 더욱 악화된다(Marini et al., 2005). 세부적으로는 발화의 통일성보다 명제밀도의 측면에 서 중고령층과 초고령층 집단 간의 차이가 더 크다고 보고된다 (Kim \& Lee, 2019).

초고령층이 임상 전 단계이자 예방적 중재를 필요로 하는 점 을 감안할 때, 자기보고 또는 의사소통 상대자의 관찰을 통한 의 사소통 평가는 객관적인 수행을 파악하는 데 유용할 수 있다. 무 엇보다 초고령층의 주관적 의사소통 양상은 신경학적 질환을 예 측하는 데 활용되기도 한다. 실제로 인지-의사소통에 대한 주관 
적 호소는 뚜렷한 객관적 저하가 발현되기 이전에 나타나는 $\mathrm{AD}$ 의 양상과 상관성이 매우 높다(Amariglio et al., 2012). 이 중 주관적 언어 호소(subjective language complaints, SLC) 는 일상적 언어능력의 만족도를 반영하는 지표로서 주관적 인 지 저하(subjective cognitive decline)나 주관적 인지 호소 (subjective cognitive complaints)와 직결된다. 55 94세의 노인을 대상으로 한 연구(Kim et al., 2015)에 따르면, 연령, 교 육연수, 직업, 우울 등이 SLC의 주요 예측변인이며 이름대기가 SLC를 가장 잘 반영하는 언어 과제이다. 주관적 및 객관적 인지의사소통 간의 상관성을 살펴본 연구(Lee, 2015; Lee \& Kim, 2021)에서 노인의 언어능력은 주의력, 기억력 등과 함께 객관적 수행을 잘 반영하는 영역으로 나타났다. 의사소통이 주로 대화 상대자를 포함한 사회적 환경 내에서 이루어짐을 감안할 때, 스 스로 인식하거나 관찰자가 판단하는 수행력이 객관적 기능을 가 늠하는 데 중요한 역할을 할 수 있다.

본 연구에서는 신경학적 질환의 고위험군인 초고령층의 특수 성에 기반하여 인지-의사소통 중재 시 활용할 수 있는 과제별 수 행 프로파일을 분석하고자 하였다. 이를 위해 80세 이상 초고령 노인을 두 집단으로 세분화해 다양한 인지-의사소통 과제를 적 용한 후 수행력을 비교하였다. 구체적인 연구 문제는 다음과 같 다. 첫째, 두 집단의 인지-의사소통 과제별 수행력을 비교하고 차 이를 분석한다. 둘째, 각 집단별로 인지와 의사소통 과제 간의 상 관성을 제시한다. 셋째, 각 집단별로 의사소통을 예측하는 인지 적 변인을 알아본다.

\section{MATERIALS AND METHODS}

\section{연구 대상}

본 연구는 수도권에 거주하는 만 80세 이상의 초고령층 노인 64명을 대상으로 하였다. 이들은 연령에 따라 80 89세 노인 35명, 90세 이상 노인 29명의 두 집단으로 분류되었다. 85세 전후의 초고령층을 대상으로 인지-의사소통 수행을 살펴본 연구가 상 대적으로 적고(Kim \& Lee, 2019), 이로 인해 연령에 따라 세분 화된 변별적 차이나 연령별 규준이 미흡하다. 본 연구에서는 이 러한 실정을 고려하여 집단을 분류하였다. 표집에는 노인정 2곳 및 대학 부설 언어재활센터를 방문한 노인, 기타 자원자가 참 여하였다. 노인 집단의 선정 기준에는 1) 만 80세 이상인 자, 2) Korean Mini-Mental State Examination (K-MMSE)의 정상군 규준(Kang, 2006)에 의거해 정상 범주에 속하는 자, 3) 신경학적 질환의 병력이 없는 자, 4) 사전 면담을 통해 신체적 및 정신적 건강 상태가 정상 범주에 속하고 청력상 문제가 없음 이 확인된 자, 5) 최소 6년 이상의 교육을 받은 자이다.

두 집단 간의 연령, 성별, 교육연수, $\mathrm{K}-\mathrm{MMSE}$ 의 분포에 대한
Table 1. Demographic and neuropsychological characteristics of subjects

\begin{tabular}{lccc}
\hline Characteristic & $\begin{array}{c}\text { Group I } \\
(\mathrm{n}=35)\end{array}$ & $\begin{array}{c}\text { Group II } \\
(\mathrm{n}=29)\end{array}$ & $t$ or $\chi^{2}$ \\
\hline Age $(\mathrm{yr})$ & $84.00 \pm 2.62$ & $93.38 \pm 1.61$ & $-17.528^{\star *}$ \\
Gender (\%) & & & 0.014 \\
Male & 42.86 & 41.38 & \\
Female & 57.14 & 58.62 & \\
Education level (yr) & $8.71 \pm 2.41$ & $8.52 \pm 2.10$ & 0.345 \\
K-MMSE & $22.83 \pm 2.47$ & $21.14 \pm 2.92$ & $2.509^{*}$ \\
Medical history & & & \\
Neurological disease & No & No & - \\
Hearing impairment & Normal & Normal & - \\
Psychiatric disorder & Normal & Normal & - \\
\hline
\end{tabular}

Values are presented as mean \pm standard deviation or number. K-MMSE: Korean Mini-Mental State Examination. ${ }^{*} p<0.05,{ }^{* *} p<$ 0.01

동질성 검정 결과, 연령 $(t=-17.528, p<0.01)$ 및 $\mathrm{K}-\mathrm{MMSE}(t=$ $2.509, p<0.05)$ 는 유의미한 차이를 보였고, 성별 $\left(x^{2}=0.014\right.$, $p=0.905)$ 과 교육연수 $(t=0.345, p=0.731)$ 의 분포상 유의한 차이는 없었다. 두 집단의 인구통계학적 및 신경심리학적 특성은 Table 1에 제시하였다.

\section{연구 도구}

작업기억 과제는 크게 구어와 비구어 영역으로 나누어 적용 하였다. 구어 작업기억은 한국판 웩슬러 성인지능검사(KoreanWechsler Adult Intelligence Scale [K-WAIS]; Yeom et al., 1992)의 숫자폭검사(digit span test)를 활용하였다. 비구어 작 업기억 과제로는 인지-의사소통장애 간편검사(Brief Test of Cognitive-Communication Disorders [BCCD]; Lee et al., 2020)의 하위검사인 '도형 모양 기억하기'를 시행하였다.

추론력 과제로는 K-WAIS의 공통성(similarity)검사를 실 시해 추상적 구어추론능력을 평가하였다. 연역적 및 귀납 적 추론은 외상성 뇌손상 환자의 인지-화용언어능력 평가도 구(Cognitive-pragmatic language ability Assessment Protocol for Traumatic Brain Injury [CAPTBI]; Lee, 2013), 수렴적 및 확산적 사고는 $\mathrm{BCCD}$ 의 각 하위검사를 활용하였다. 문제해결의 구어 과제는 $\mathrm{BCCD}$ 의 문제추론, 관점 해석 및 전이, 비구어 과제는 $\mathrm{CAPTBI}$ 의 문제해결 영역이 포함되었다. 집행기 능 과제는 기호잇기검사(Trail Making Test [TMT]; Park \& Choi, 2003)의 과제 전환, $\mathrm{BCCD}$ 의 계획화, $\mathrm{CAPTBI}$ 의 실행화 검사로 구성되었다.

의사소통 과제는 의미적 및 화용적 측면, 주관적 의사소통으 로 분류되었다. 의미적 과제 중 대면이름대기는 한국판 보스톤 
Table 2. Assessment tools

\begin{tabular}{llc}
\hline Domain & \multicolumn{1}{c}{ Task } & Tool \\
\hline Working memory & Verbal: digit span & K-WAIS \\
& Nonverbal: recall of figure & BCCD \\
Reasoning & Similarity (abstract verbal reasoning) & K-WAIS \\
& Deductive/inductive reasoning & CAPTBI \\
& Convergent/divergent thinking & BCCD \\
Problem solving & Verbal: making inferences/ & BCCD \\
& interpreting perspective/ & \\
& transferring insights & \\
& Nonverbal: problem solving & CAPTBI \\
Executive function & Task switching & TMT \\
& Planning & BCCD \\
& Activating & CAPTBI \\
\hline Communication & Confrontation naming & K-BNT-15 \\
& Word fluency & PK-WAB-R \\
& Word definition & BCCD \\
& Discourse & BCCD \\
& Pragmatic expression & BCCD \\
& Subjective communication & ISCOLE \\
\hline
\end{tabular}

K-WAIS: Korean-Wechsler Adult Intelligence Scale, BCCD: Brief Test of Cognitive-Communication Disorders, CAPTBI: CognitivePragmatic Language Ability Assessment Protocol for Traumatic Brain Injury, TMT: Trail Making Test, K-BNT-15: Short Form of the Korean Version-the Boston Naming Test, PK-WAB-R: Paradise KoreaWestern Aphasia Battery Revised, ISCOLE: Informant-Report Scale on Cognitive-Linguistic Abilities of the Elderly

이름대기검사 단축형(Short Form of the Korean Version-the Boston Naming Test; Kim \& Kim, 2013), 단어유창성은 파 라다이스 한국판 웨스턴 실어증검사 개정판(Paradise KoreaWestern Aphasia Battery Revised; Kim \& Na, 2012)의 통 제단어연상, $\mathrm{BCCD}$ 의 단어정의 하위검사가 적용되었다. 화용 적 과제는 $\mathrm{BCCD}$ 의 담화 및 화용 표현으로 구성되었다. 담화 는 문단 자극을 제시한 후 '다시 말하기' 과제를 시행하여 응집 성(cohesion), 통일성(coherence), 명제, 쉼을 분석하며, 화 용 표현에서는 지시문을 듣고 상황에 맞게 적절히 표현하는 능 력을 평가한다. 주관적 의사소통은 노년기 인지-언어능력에 대 한 정보제공자 보고형 평가척도(Informant-Report Scale on Cognitive-Linguistic Abilities of the Elderly [ISCOLE]; Lee \& Kim, 2021)의 언어 영역을 자기 보고형(self-report)으 로 전환하여 대상자 본인이 직접 평가하도록 하였다. 본 연구에 활용된 인지-의사소통 과제는 Table 2 와 같다.

\section{연구 절차}

인구통계학적 및 신경학적 정보, 기타 능력(청력, 시력 등)에
대한 사례면담을 실시하였고, 정상군의 선별 및 전반적 인지 수 준을 알아보기 위해 K-MMSE를 시행하였다. 이에 따라 선별된 대상군에게 5 개 인지-의사소통 영역에 해당하는 총 16 개 과제 를 1 2회에 걸쳐 적용하였다. 검사는 소음이 최소화된 조용한 방에서 일대일 직접 평가 방식으로 진행되었고, 주관적 평가인 ISCOLE는 평정 방법을 숙지하도록 한 후 대상자가 스스로 시행 한 경우가 대부분이었으나, 신체적 문제(예: 시력, 팔의 움직임)나 개별적 요청이 있을 경우 검사자가 문항을 읽어 주고 반응을 기 재하였다.

채점은 각 과제별로 다양하였다. 작업기억 중 숫자 폭 바로 따 라말하기는 3 9개, 거꾸로 따라말하기는 2 8개의 목록으로 구 성되며, 각 과제의 최다 수행 개수를 0 17점의 범위로 합산하여 산정하였다. 비구어 작업기억은 도형의 순서를 거꾸로 기억하여 반응하도록 하고, 2점(정반응 4개), 1점(정반응 3개), 0점(정반응 2개 이하)으로 채점하였다. 추론력 과제 중 공통성검사는 주어 진 두 어휘 간의 공통점을 묻는 14 개 문항에 대해 채점 기준에 따라 0 2점, 최대 28점으로 산정하였다. 연역적 및 귀납적 추론 은 각 2개씩 총 4 개 문항에 대해 최대 8점을 부여하였고, 수렴적 및 확산적 사고는 총 2 개 문항을 정반응 수, 자가수정 등에 근거 해 0 2점으로 채점하였다. 문제해결 구어 과제의 문제추론, 관 점 해석 및 전이는 제시된 채점 기준(예: 기준에 명시된 내용 중 한 가지 표현 2점, 정확한 내용은 아니나 수용 가능한 정보 및 적 절한 언어적 표현 1점)에 따라 총 2개 문항에 0 4점을 부여하였 다. 문제해결 비구어 영역의 1 개 문항은 채점 기준에 따라 최대 2점까지 산정하였다. 집행기능 과제 중 TMT는 기존의 'part B' 에서 알파벳을 한글 자음으로 교체한 검사를 적용하여 반응시 간을 점수화하였다. 계획화는 채점 기준에 근거해 1 개 문항에 최 대 2점을 부여하였고, 실행화의 1개 문항은 2점(필요도구 사용 해 독립적 수행/적절한 언어적 수행), 1점(언어적- 행동적 단서 후 정반응/적절한 언어적 수행), 0점(기타 반응)으로 산정하였다.

총 6개 영역으로 구성된 의사소통 과제 중 대면이름대기는 흑 백 선으로 그려진 15 개 명사에 대해 자발적으로 정반응한 개수 로 산정하였다. 단어유창성은 1 분 동안 '동물' 범주에 해당하는 단어를 최대한 많이 말하도록 한 후 피검자가 산출한 이름의 개 수로 채점하였다. 이때 오반응은 점수 산정에서 제외하였고 중복 된 반응은 1 회만 정반응으로 간주하였다. 단어정의는 피검자의 반응을 핵심 및 부수 의미로 구분해 0 2점을 부여하였다. 담화는 명시된 기준에 따라 통일성 0 3점, 응집성 0 2점, 명제 0 2점, 쉼 0 1점 등 최대 8점까지 산정하였고, 화용 표현 1개 문항은 2점(상대방의 확인을 요청하는 공손한 표현이 포함된 경우), 1점 (직설적인 내용만 포함된 경우), 0 점(기타 반응)을 부여하였다. 주 관적 의사소통은 이해, 표현, 이름대기, 읽기, 쓰기, 계산, 화용과 관련된 8 개 문항에 대해 1년 전과 비교한 자신의 능력을 스스로 
평가하도록 하였다. '아니다(0)-약간 그렇다(1)-보통이다(2)-많 이 그렇다(3)-항상 그렇다(4)'의 5점 척도로 평정하였으며, 점수 가 높을수록 수행력이 낮은 것으로 해석되었다.

\section{통계 분석}

본 연구에서는 통계분석 프로그램으로서 SPSS version 21.0 (IBM Corp., Armonk, NY, USA)이 활용되었다. 연구 대상의 인구통계학적 변인을 통제하고 집단별 기술통계 및 차이를 알아 보기 위해 독립표본 $t$-검정(independent samples $t$-test) 및 카이제곱 검정(chi-squared test)을 실시하였다. 각 과제 간의 상관성은 피어슨 상관계수(Pearson correlation coefficient) 분석을 활용하였고, 의사소통 능력을 예측하는 인지 과제는 단 계적 다중선형 회귀분석(stepwise multiple linear regression analysis)을 통해 알아보았다.

\section{RESULTS}

\section{과제별 수행력의 비교}

인지-의사소통의 과제별로 두 집단의 수행력에 차이가 있는지 를 비교한 결과는 Table 3에 제시하였다. 인지 과제 중 작업기억 (구어 및 비구어), 추론력(공통성, 연역적 및 귀납적 추론, 수렴적 및 확산적 사고), 집행기능(과제 전환, 계획화, 실행화)의 모든 과 제는 두 집단 간에 유의한 차이를 보였다 $(p<0.05$ 또는 $p<0.01)$. 반면 문제해결의 구어 및 비구어 과제는 집단 간의 차이가 유의
하지 않았다. 의사소통 과제는 단어정의를 제외하고 대면이름대 기 $(p<0.01)$, 단어유창성 $(p<0.01)$, 담화 $(p<0.01)$, 화용 표현 $(p$ $<0.05)$, 주관적 의사소통 $(p<0.05)$ 에서 모두 유의미한 차이가 있었다.

\section{인지-의사소통 과제 간의 상관성}

두 집단에서 인지와 의사소통 과제 간의 상관성을 알아보았 다. 집단 I의 대면이름대기, 단어유창성, 단어정의, 담화, 화용 표 현, 주관적 의사소통은 모든 인지 과제 $(p<0.05$ 또는 $p<0.01)$ 와 유의미한 상관성을 보였다(Table 4). 집단 II는 단어유창성 및 화용 표현이 모든 인지 과제 $(p<0.05$ 또는 $p<0.01)$ 와 유의한 상관성이 있었다(Table 5). 대면이름대기는 집행기능의 실행화 를 제외한 나머지 인지 과제와의 상관성이 유의하였다 $(p<0.05$ 또는 $p<0.01)$. 단어정의는 구어 작업기억 $(r=0.376, p<0.05)$, 비구어 문제해결력 $(r=0.423, p<0.05)$, 집행기능의 계획화 $(r=$ $0.451, p<0.05)$ 와 유의미한 상관관계가 있었다. 담화는 집행기 능의 계획화 및 실행화를 제외한 나머지 인지 과제와 상관성이 유의하였다 $(p<0.01)$. 주관적 의사소통도 집행기능의 계획화 및 실행화를 제외하고 모든 인지 과제와 유의한 상관성이 있었다( $p$ $<0.05$ 또는 $p<0.01)$.

\section{의사소통의 인지적 예측변인}

두 집단의 의사소통을 예측하는 인지 과제가 무엇인지를 분 석한 결과는 Table 6과 Table 7에 제시하였다. 집단 I의 대면

Table 3. Comparison of group average and standard deviation for cognitive-communication in two groups

\begin{tabular}{|c|c|c|c|c|}
\hline Task & Group I & Group II & $t$ & $p$-vlaue \\
\hline WM: verbal & $4.03 \pm 2.38$ & $2.66 \pm 2.70$ & 2.160 & $<0.05$ \\
\hline WM: nonverbal & $1.03 \pm 0.66$ & $0.34 \pm 0.48$ & 4.621 & $<0.01$ \\
\hline Rs: similarity & $12.63 \pm 3.41$ & $6.62 \pm 4.74$ & 5.884 & $<0.01$ \\
\hline Rs: deductive/inductive & $5.71 \pm 1.20$ & $4.45 \pm 2.20$ & 2.777 & $<0.01$ \\
\hline Rs: convergent/divergent & $2.74 \pm 0.82$ & $1.97 \pm 1.24$ & 3.008 & $<0.01$ \\
\hline PS: verbal & $3.11 \pm 1.57$ & $2.45 \pm 2.11$ & 1.406 & 0.166 \\
\hline PS: nonverbal & $0.97 \pm 0.66$ & $0.79 \pm 0.77$ & 0.993 & 0.325 \\
\hline EF: task switching & $91.00 \pm 38.18$ & $175.41 \pm 41.46$ & -8.469 & $<0.01$ \\
\hline EF: planning & $1.00 \pm 0.69$ & $0.38 \pm 0.49$ & 4.074 & $<0.01$ \\
\hline EF: activating & $0.91 \pm 0.70$ & $0.28 \pm 0.45$ & 4.217 & $<0.01$ \\
\hline Confrontation naming & $9.00 \pm 2.46$ & $5.00 \pm 2.84$ & 6.035 & $<0.01$ \\
\hline Word fluency & $11.77 \pm 3.23$ & $8.48 \pm 2.92$ & 4.233 & $<0.01$ \\
\hline Word definition & $0.97 \pm 0.66$ & $1.17 \pm 0.66$ & -1.210 & 0.231 \\
\hline Discourse & $5.88 \pm 0.52$ & $2.85 \pm 1.06$ & 14.006 & $<0.01$ \\
\hline Pragmatic expression & $0.91 \pm 0.66$ & $1.40 \pm 0.85$ & 2.152 & $<0.05$ \\
\hline Subjective communication & $0.55 \pm 0.69$ & $3.55 \pm 2.26$ & -4.850 & $<0.05$ \\
\hline
\end{tabular}

Values are presented as mean \pm standard deviation. WM: working memory, Rs: reasoning, PS: problem solving, EF: executive function 
Table 4. Correlation coefficient between cognitive and communication ability in group I

\begin{tabular}{lcccccc}
\hline & \multicolumn{5}{c}{ Communication } \\
\cline { 2 - 6 } Cognition & $\begin{array}{c}\text { Confrontation } \\
\text { naming }\end{array}$ & Word fluency & Word definition & Discourse & $\begin{array}{c}\text { Pragmatic } \\
\text { expression }\end{array}$ & $\begin{array}{c}\text { Subjective } \\
\text { communication }\end{array}$ \\
\hline WM: verbal & $0.918^{* *}$ & $0.907^{* *}$ & $0.689^{* *}$ & $0.769^{* *}$ & $0.602^{* *}$ & $-0.793^{* *}$ \\
WM: nonverbal & $0.882^{* *}$ & $0.841^{* *}$ & $0.603^{* *}$ & $0.674^{* *}$ & $0.544^{* *}$ & $-0.701^{* *}$ \\
\hline Rs: similarity & $0.956^{* *}$ & $0.934^{* *}$ & $0.709^{* *}$ & $0.798^{* *}$ & $0.692^{* *}$ & $-0.720^{* *}$ \\
Rs: deductive/inductive & $0.805^{* *}$ & $0.832^{* *}$ & $0.616^{* *}$ & $0.717^{* *}$ & $0.414^{*}$ & $-0.866^{* *}$ \\
Rs: convergent/divergent & $0.805^{* *}$ & $0.836^{* *}$ & $0.583^{* *}$ & $0.742^{* *}$ & $0.505^{* *}$ & $-0.825^{* *}$ \\
PS: verbal & $0.915^{* *}$ & $0.918^{* *}$ & $0.767^{* *}$ & $0.748^{* *}$ & $0.779^{* *}$ & $-0.678^{* *}$ \\
PS: nonverbal & $0.756^{* *}$ & $0.725^{* *}$ & $0.666^{* *}$ & $0.586^{* *}$ & $0.735^{* *}$ & $-0.450^{* *}$ \\
EF: task switching & $-0.842^{* *}$ & $-0.841^{* *}$ & $-0.561^{* *}$ & $-0.697^{* *}$ & $-0.495^{* *}$ & $0.765^{* *}$ \\
EF: planning & $0.766^{* *}$ & $0.731^{* *}$ & $0.711^{* *}$ & $0.607^{* *}$ & $0.716^{* *}$ & $-0.455^{* *}$ \\
EF: activating & $0.749^{* *}$ & $0.705^{* *}$ & $0.626^{* *}$ & $0.630^{* *}$ & $0.684^{* *}$ & $-0.386^{* *}$ \\
\hline
\end{tabular}

WM: working memory, Rs: reasoning, PS: problem solving, EF: executive function. ${ }^{*} p<0.05 .{ }^{* *} p<0.01$

Table 5. Correlation coefficient between cognitive and communication ability in group II

\begin{tabular}{lcccccc}
\hline & \multicolumn{3}{c}{ Communication } \\
\cline { 2 - 7 } Cognition & $\begin{array}{c}\text { Confrontation } \\
\text { naming }\end{array}$ & Word fluency & Word definition & Discourse & $\begin{array}{c}\text { Pragmatic } \\
\text { expression }\end{array}$ & $\begin{array}{c}\text { Subjective } \\
\text { communication }\end{array}$ \\
\hline WM: verbal & $0.693^{* *}$ & $0.903^{* *}$ & $0.376^{*}$ & $0.769^{* *}$ & $0.761^{* *}$ & $-0.722^{* *}$ \\
WM: nonverbal & $0.442^{*}$ & $0.611^{* *}$ & 0.031 & $0.565^{* *}$ & $0.375^{*}$ & $-0.572^{* *}$ \\
\hline Rs: similarity & $0.414^{*}$ & $0.836^{* *}$ & 0.228 & $0.851^{* *}$ & $0.572^{* *}$ & $-0.750^{* *}$ \\
Rs: deductive/inductive & $0.606^{* *}$ & $0.866^{* *}$ & 0.266 & $0.831^{* *}$ & $0.588^{* *}$ & $-0.864^{* *}$ \\
\hline Rs: convergent/divergent & $0.649^{* *}$ & $0.883^{* *}$ & 0.314 & $0.778^{* *}$ & $0.738^{* *}$ & $-0.796^{* *}$ \\
PS: verbal & $0.755^{* *}$ & $0.906^{* *}$ & 0.327 & $0.754^{* *}$ & $0.759^{* *}$ & $-0.756^{* *}$ \\
PS: nonverbal & $0.504^{* *}$ & $0.677^{* *}$ & $0.423^{*}$ & $0.545^{* *}$ & $0.492^{* *}$ & $-0.463^{*}$ \\
EF: task switching & $-0.630^{* *}$ & $-0.796^{* *}$ & -0.144 & $-0.713^{* *}$ & $-0.630^{* *}$ & $0.833^{* *}$ \\
EF: planning & $0.586^{* *}$ & $0.438^{*}$ & $0.451^{*}$ & 0.350 & $0.520^{* *}$ & -0.322 \\
EF: activating & 0.111 & $0.380^{*}$ & 0.313 & 0.326 & $0.411^{*}$ & -0.223 \\
\hline
\end{tabular}

WM: working memory, Rs: reasoning, PS: problem solving, EF: executive function. ${ }^{\star} p<0.05 .{ }^{* *} p<0.01$

Table 6. Cognitive predictive tasks of communication ability in group I

\begin{tabular}{ll}
\hline Communication & $\beta$-value \\
\hline Confrontation naming & \\
WM: verbal & $0.125^{*}$ \\
Rs: similarity & $0.134^{* *}$ \\
Word fluency & \\
PS: verbal & $0.479^{*}$ \\
Word definition & - \\
Discourse & - \\
Pragmatic expression & \\
PS: verbal & $0.887^{*}$ \\
Subjective communication & \\
Rs: deductive/inductive & $-0.694^{*}$ \\
Rs: convergent/divergent & $-0.490^{*}$ \\
\hline
\end{tabular}

WM: working memory, Rs: reasoning, PS: problem solving, EF: executive function. ${ }^{*} p<0.05 .{ }^{* *} p<0.01$
Table 7. Cognitive predictive tasks of communication ability in group II

\begin{tabular}{lc}
\hline Communication & $\beta$-value \\
\hline Confrontation naming & $1.085^{\star}$ \\
PS: verbal & $0.337^{\star}$ \\
EF: planning & - \\
Word fluency & - \\
Word definition & \\
Discourse & $2.272^{*}$ \\
Rs: similarity & - \\
Pragmatic expression & \\
Subjective communication & $-0.608^{*}$ \\
Rs: deductive/inductive & $0.707^{* *}$ \\
EF: task switching & PS:
\end{tabular}

WM: working memory, Rs: reasoning, PS: problem solving, EF: executive function. ${ }^{*} p<0.05 .{ }^{* *} p<0.01$ 
이름대기는 구어 작업기억 $(\beta=0.125, p<0.05)$ 및 추론력의 공통성 $(\beta=0.134, p<0.01)$, 단어유창성은 구어 문제해결력 ( $\beta=0.479, p<0.05)$, 화용 표현은 구어 문제해결력 $(\beta=0.887$, $p<0.05)$ 과제를 통해 각각 예측되었다. 주관적 의사소통은 추 론력의 3개 과제인 공통성 $(\beta=1.017, p<0.05)$, 연역적 및 귀납적 추론( $\beta=-0.694, p<0.05)$, 수렴적 및 확산적 사고 $(\beta=-0.490$, $p<0.05)$ 과제가 예측변인으로 분석되었다. 단어정의와 담화 를 예측하는 유의한 인지 과제는 없는 것으로 나타났다. 집단 II 의 대면이름대기는 구어 문제해결력 $(\beta=1.085, p<0.05)$ 및 집 행기능의 계획화 $(\beta=0.337, p<0.05)$, 담화는 추론력의 공통 성 $(\beta=2.272, p<0.05)$, 주관적 의사소통은 추론력의 연역적 및 귀납적 추론 $(\beta=-0.608, p<0.05)$ 및 집행기능의 과제 전환 ( $\beta=707, p<0.01)$ 을 통해 예측할 수 있었다. 반면 단어유창성, 단어정의, 화용 표현은 유의미한 예측변인에 해당하는 인지 과제 가 없었다.

\section{DISCUSSIONS}

본 연구는 초고령층의 인지-의사소통 중재에 활용하기 위한 과제별 수행 프로파일을 제시하는 데 목적을 두었다. 이를 위해 80 89세 및 90세 이상 초고령층 집단에 인지-의사소통 과제를 적용한 후 과제별 수행력을 비교하였다. 또 각 집단별로 인지와 의사소통 과제 간의 상관성 및 의사소통을 예측하는 인지적 변 인을 제시하였다.

\section{과제별 수행력의 비교: 인지-의사소통 수행 프로파일}

작업기억은 전반적인 인지-언어 영역에 영향을 미치는 핵심 영역으로서 모든 고차원적 인지-의사소통 수행의 근간을 이룬 다(Matysiak et al., 2019). 이로 인해 초고령층의 인지-의사소 통 중재 시 우선적으로 고려되며, 작업기억의 효율성이 다른 영 역의 기능적 향상을 반영하는 지표가 된다. 특히 구어 작업기억 은 언어적 처리와의 상관성이 높은 것으로 보고되며, 전반적 인 지 자원으로서 비구어 작업기억 기제의 수행도 뒷받침되어야 한 다(Seniów et al., 2009). 이는 구어 및 비구어 작업기억에서 두 집단 간의 차이가 유의하게 나타난 본 연구 결과와도 연계된다. 또 90세 이상 초고령층을 대상으로 한 종단 연구(Melikyan et al., 2019)에서 숫자 폭과 같은 작업기억 과제가 매우 중요한 지 표로 지목된 바 있다. 비구어 작업기억 과제인 '도형 모양 기억 하기'는 연소, 중고령, 초고령 노인뿐 아니라 경도인지장애(mild cognitive impairment, MCI) 및 치매 집단의 수행을 민감하게 반영한다고 알려져 있다(Lee et al., 2020). 실제로 작업기억 용 량을 증진시키는 중재를 통해 언어능력으로의 원전이 효과를 야 기하기도 한다. 즉 작업기억 용량이 확장되면 이전에 비해 더 많
은 항목을 동시에 보유할 수 있기 때문에 언어 처리를 활성화시 키는 데 기여한다(Lee \& Kim, 2020). 80 89세와 90세 이상 집단 간의 작업기억 수행에 변별적 차이를 규명한 본 결과를 통 해, 구어 및 비구어 작업기억 과제가 초고령층에 대한 예방적 중 재 시 필수적으로 고려되어야 할 요소임을 알 수 있었다.

본 연구에서 추론력과 집행기능도 연령효과가 나타났다. 이 러한 고차원적 인지는 다양한 인지-언어 과제의 기반이 되는데 (Lee, 2021), 새로운 상황에서 정보, 방법, 개념, 이론을 활용하 고 결과를 예측함으로써 해결을 위한 접근법을 선택하고 다양한 정보의 질과 중요성, 결과의 가능성을 판단한다. 이 과정에서 추 론에 근거한 선택과 범주의 적용, 분석, 평가가 동반된다. 따라서 초고령층에 대한 예방적 중재 시 추론력, 집행기능 등의 고차원 적 인지를 요하는 과제를 고안할 필요가 있다. 이 같은 맥락을 고 려할 때 본 연구에서 공통성, 연역적 및 귀납적 추론, 수렴적 및 확산적 사고로 구성된 추론력 그리고 과제 전환, 계획화, 실행화 등 집행기능의 수행이 집단 간에 차이를 보인 것은 매우 중요한 함의를 갖는다. 특히 집행기능은 연령 효과가 가장 강력히 반영 되는 인지 영역으로 꼽힌다(Bakos et al., 2008; Lee, 2021). 초 고령층에서 관찰되는 집행기능의 민감도는 추론에 기반한 상관 성을 인식하고 통합하며 집행적 처리를 효율화하는 능력과 연관 된다(Bakos et al., 2008). 이러한 복잡성이 반영된 TMT 등의 집행기능 과제가 임상적으로 보편화되어 있는 것도 초고령층의 특수성을 고려한 결과로 간주된다.

의사소통 과제의 측면에서 대면이름대기, 단어유창성, 담화, 화용 표현 등은 90세 이상 초고령 집단에서 수행력의 저하가 두 드러졌다. 이들은 주로 어휘-의미적 차원의 의사소통기능을 반 영하는 과제로서, 작업기억, 고차원적 인지 등과 연계되어 노화 및 신경학적 변화에 매우 민감하다고 알려져 있다(Lee et al., 2020). 예를 들어, 초고령층일수록 대면이름대기, 단어유창성 등의 의미적 수행이 급격히 저하된다는 보고가 많다(Lee et al., 2020; Whittle et al., 2007). 특히 화용 표현은 정보의 이해 및 처리 속도, 작업기억, 집행기능 등과 고루 연계되므로 초고령층 의 어휘-의미적 처리에 부정적으로 작용한다. 나이가 들수록 적 절한 정보에 대한 민감도가 떨어지기 때문에 그림 설명하기, 특 정 주제에 대해 말하기, 다시 말하기 등의 담화 과제에서 발화의 명제밀도가 매우 저하된다(Lee et al., 2020).

주관적 의사소통은 일생생활에서 느끼는 언어적 만족도를 반 영하기 때문에 신경학적 질환의 전조 증상으로서 임상적 함의 가 큰 영역이다. 특히 전반적 인지-언어능력과의 상관성이 입증 되면서, 일상적이고 기능적인 의사소통을 반영하고 객관적인 수 행력을 보완하는 지표로서 널리 활용되고 있다(Lee \& Kim, 2021). 본 연구에서는 1년 전과 비교한 언어 수행력(이해, 표현, 이름대기, 읽기, 쓰기, 계산, 화용)을 자기 보고형으로 평가한 결 
과 두 연령 집단 간에 유의미한 차이가 있었다. 즉 90세 이상 노 인은 상대적으로 자신의 의사소통 능력이 낮다고 인식하며, 이 는 주관적 인지 호소에 대한 여러 연구 선행 연구들과 맥을 같이 한다(Amariglio et al., 2012; Kim et al., 2015; Lee \& Kim, 2021).

한편, 본 연구에서 문제해결력(구어 및 비구어)과 단어정의 과 제는 집단 간의 차이가 유의하지 않았다. 문제해결력은 청년기에 서 중년기 초까지 발달하다 50세 이후부터 점차 저하되는데, 축 적된 경험이나 지식의 양적 확대가 오히려 노인의 문제해결에 긍 정적으로 작용한다는 견해도 있다(Lee, 2021). 또 인지능력 및 기술의 적용, 일상적 경험, 복합적이고 다차원적 시각 등이 수행 의 변인으로 작용할 수 있는데, 단어정의도 이 같은 변수들의 영 향을 받는 과제이다. 문장 수준의 의미론적 표현을 넘어 의미적 처리, 의미지식, 상위언어(metalinguistic)능력, 고차원적 인지 등이 연계되기 때문에 본 연구 내 두 연령 집단의 차이를 민감하 게 반영하지 못한 것으로 간주된다.

\section{인지-의사소통 과제 간의 상관성: 인지-의사소통 상관 프로파일}

본 연구의 두 집단은 단어유창성과 화용 표현이 모든 인지 과 제와 유의한 상관성을 보였다. 단어유창성의 연령효과는 언어 지 식 자체의 손실보다는 전반적인 정보 처리 과정의 결함에 기인 한다고 알려져 있다(Lee et al., 2020). 초고령층으로 갈수록 작 업기억 용량이 감소하면서 어휘를 효율적으로 연상하지 못하기 때문이다. 실제로 Lee et al.(2020)의 연구에서 55 64세의 연 소 노인층에 비해 75세 이상 집단의 단어유창성이 유의하게 낮 았다. 이는 단어유창성 과제를 수행하기 위한 인지적 기제와 연 관된다. 즉 초고령층은 의미기억 내에서 개념의 형성 및 추론, 의 미 정보의 인출과 연계를 통해 개념적 지식을 처리하는 데 어려 움이 있기 때문에 단어유창성의 수행이 현저히 저하된다(Lee, 2021; Unsworth et al., 2012). 본 연구에서 적용한 의미적 단 어유창성의 경우 주의력, 처리 속도, 작업기억 용량, 집행기능과 의 상관성이 높다고 보고된 바 있다(Klencklen et al., 2017; Lee, 2021). 연령이 높을수록 기억력과 고차원적 인지가 단어 유창성에 미치는 영향이 커진다는 연구 결과도 있다(Peach \& Shapiro, 2020). 이는 본 연구의 두 초고령 집단에서 단어유창 성과 모든 집행기능 과제들 간에 유의한 상관성을 보인 결과와도 동일한 맥락이다.

화용 표현은 정보의 이해 및 처리 속도, 작업기억, 집행기능 등과 연계되어 언어의 의미와 구문, 화용 측면을 통합적으로 반 영한다(Lee, 2021; Marini et al., 2005). 이의 수행은 75세를 기점으로 더욱 악화되는데(Marini et al., 2005), 복잡한 문맥 을 표현하기 어렵고 정보를 효율화하지 못하는 양상이 심화된 다. 또 표현하고자 하는 의도를 문맥에 맞게 순서화하는 데 어
려움이 있을 뿐 아니라 적절한 정보에 민감하게 반응하지 못한 다(Peach \& Shapiro, 2020). 연령이 높을수록 상황에 맞는 표현을 지속할 수 없는 양상은 사회적 상호작용과도 연계된다 (Keller-Cohen et al., 2006). 즉 사회적 의사결정, 문제해결, 일관적 판단, 사회적 및 기능적 의사소통에 부정적인 영향을 미 친다(Lee, 2021). 이러한 사회적 측면은 초고령층의 인지 저하 를 설명하는 강력한 변인이므로(Keller-Cohen et al., 2006), 화용 표현의 수행력을 파악하는 것은 의미 있는 임상적 시사점 을 갖는다.

본 연구에서 집단 I과 유사하게 집단 II의 대면이름대기, 담화, 주관적 의사소통도 대부분의 인지 과제와 상관성이 높았다. 연 령이 높을수록 이름대기 과제를 수행할 때 목표어와 의미적으로 연관된 다른 어휘를 산출하고 반응시간이 지연되는 경향이 있다 (Lee, 2021; Peach \& Shapiro, 2020). 예컨대, 초고령 노인은 대면이름대기 자극에 대한 의미적 접근이 가능함에도 불구하고 사물의 이름을 산출하기가 어려워진다. 본 연구에서 90 세 이상 집단의 대면이름대기가 작업기억이나 고차원적 인지와 상관성을 보인 것은 어휘-의미적 접근을 뒷받침하는 인지적 처리 기제와 관련된다. 대면이름대기와 단어유창성의 프로파일이 유사한 것 도 이 같은 이유에 근거한다.

담화의 경우 초고령층의 속성을 보다 민감하게 반영한다. 특 히 주제에서 벗어난 장황한 발화가 증가하는데, 이는 다음의 세 가지 근거로써 설명된다(Kim \& Lee, 2019; Marini et al., 2005). 첫째, 담화 산출 시 사전적 지식에 접근하고 통사론적 계획을 시행하는 데 기능적인 결함이 있다. 둘째, 작업기억에서 불필요한 정보를 억제하지 못하는 억제 결함 모델(inhibitory deficit model)에 근거해 발화가 장황해지는 경향이 있다. 즉 불 필요한 정보를 억제하지 못함으로써 보다 많은 불필요한 정보가 활성화되면서 이를 억제하기 위한 효율성이 저하된다. 셋째, 노 년층에 적용 가능한 화용론적 변화 가설(pragmatic change hypothesis)을 고려할 때, 발화 목적에 맞는 객관적 및 일관적 주제 대신 개인적 내러티브, 회상담(reminiscence), 정체성에 편중되는 양상을 보인다. 이처럼 담화가 갖는 다차원적 속성은 초고령층의 수행에 어려움을 가중시킨다. 예컨대, 평균 연령 79세 및 90세인 두 고령 집단에서 전반적 인지 능력이 저하될수록 담 화의 통일성은 낮았다(Kim \& Lee, 2019).

초고령층의 주관적 의사소통이 신뢰도 높은 지표로서 기능하 기 위해서는 객관적 수행력과의 상관성이 주요 관건이 된다. 예 를 들어, 노인의 기억력, 조직화능력, 추론력은 자기보고형에 근 거한 주관적 의사소통을 통해 가장 잘 예측된다(Lee, 2021). 본 연구의 주관적 의사소통 수행은 집단 I의 전반적 인지 과제, 그리 고 집단 II의 작업기억, 추론력, 문제해결력 과제와 상관성이 높 았다. 주관적 의사소통과 인지 과제 간의 상관성은 초고령층에 
대한 중재 시 효율성을 극대화하는 데 활용될 수 있다.

한편, 본 연구에서 집단 $\mathrm{II}$ 의 단어정의 수행은 집단 $\mathrm{I}$ 의 양상 과 다소 차이를 보였다. 집단 $\mathrm{II}$ 의 단어정의는 특히 구어 작업기 억, 집행기능의 계획화 과제 등과 유의미한 상관성이 있었다. 이 는 단어정의가 의미론적 표현에 그치지 않고 어휘-의미 처리, 사 물 관련 의미지식, 상위언어 능력, 고차원적 인지와 같은 다양한 변인에 좌우되기 때문이다(Keller-Cohen et al., 2006; Lee, 2021). 초고령층의 단어정의 중재 시 이러한 속성을 고려하면 중 재 효과성을 높이는 데 기여할 것으로 보인다.

\section{의사소통의 인지적 예측변인: 인지-의사소통 예측 프로파일}

본 연구를 통해 두 연령 집단의 의사소통을 예측하는 인지 과 제를 제시하였다. 분석된 예측변인은 다음과 같은 속성을 갖는 다. 첫째, 구어 작업기억, 구어 문제해결력과 같은 구어 하위 과 제를 통해 예측되는 의사소통 영역이 많았다. 예를 들어, 집단 I 의 대면이름대기는 구어 작업기억, 생성이름대기 및 화용 표현은 구어 문제해결력, 그리고 집단 II의 대면이름대기는 구어 문제해 결력이 주요 예측변인이었다. 구어 인지 과제가 주로 인지 화용 론적(cognitive pragmatics) 측면에서 논의되는 경우가 많은 점을 고려할 때 이 같은 결과의 임상적 함의가 매우 크다. 예를 들어, 초고령층에 대한 의사소통 중재 시 작업기억이나 문제해결 력에 기반한 구어 과제를 고안하면 중재 효과를 극대화할 수 있 다(Lee \& Kim, 2020).

둘째, 추론력의 공통성 과제는 다수의 의사소통 영역을 민감 하게 반영하는 것으로 나타났다. 즉 집단 I의 대면이름대기 및 주관적 의사소통, 집단 II의 담화는 공통성 과제를 통해 잘 예측 되었다. 본 연구에 활용된 공통성 과제는 추상적 구어추론기능 을 요하는데, 이러한 구어적 속성이 의사소통의 주요 영역을 수 행하는 데 크게 기여한 것으로 간주된다(Maseda et al., 2014). 특히 초고령층은 문장의 복잡성, 통사적 및 사전적 산출 오류 등 의 미시언어적(microlinguistic) 능력이 비교적 보존되는 반면, 통일성, 응집성, 정보성과 같은 거시언어적(macrolinguistic) 능 력이 저하된다(Kim \& Lee, 2019). 이러한 속성은 구어적 추론 과 같은 인지 기제의 효율적 처리를 필수적으로 요한다.

셋째, 주관적 의사소통을 예측하는 인지적 하위 과제가 다양 하게 나타났다. 집단 I은 추론력의 모든 세 하위 과제, 집단 II는 추론력 및 집행기능의 하위 과제를 통해 고루 예측되었다. 이는 집단 I의 주관적 의사소통이 전반적 인지와 상관성을 보인 결과 와도 맥을 같이한다. 연령이 높아질수록 일상생활에서 다양한 주관적 호소가 발생하는데, 실제로 노인 인구의 50 60\%가 인 지나 언어 수행상의 불편함을 겪는다(Lee, 2021). 주관적 호소 가 노화의 보편화된 양상인 점, 주관적 의사소통과 연계된 인지 과제가 다양한 점, 주관적 언어 또는 인지 호소가 일상생활에 미
치는 영향이 광범위한 점 등을 고려할 때, 본 결과가 초고령층의 삶의 질을 가늠하는 주요 근거로서 활용될 수 있다(Amariglio et al., 2012; Kim et al., 2015; Lee, 2015).

요컨대, 본 연구는 초고령층의 인지-의사소통에 대한 수행 프 로파일, 상관 프로파일, 예측 프로파일을 분석함으로써 인지-의 사소통 중재 시 증거 기반적 근거로써 활용하고자 하였다. 이는 인지-의사소통 중재의 효과를 극대화하고 신경학적 질환으로의 진전을 예방하는 데 기여할 것이다. 본 연구의 제한점 및 향후 연 구를 위한 제언은 다음과 같다. 첫째, 고령화 추세가 가속화됨 에 따라 초고령층의 인지-의사소통 프로파일을 명확화할 필요 가 있으므로 연령 범주를 보다 세분화해야 할 것이다. 예를 들어, 80 대를 초반 및 중반으로 분류하거나 90 세 이상 집단을 구체화 한 분석이 필요하다. 둘째, 인지 및 의사소통의 하위 과제를 다양 하게 구성함으로써 다영역적 프로파일을 제시할 필요가 있다. 즉 본 연구에 포함되지 않은 기억의 하위 영역, 담화의 하위 과제, 비유언어 등이 추가적으로 포함될 수 있다. 셋째, 신경학적 질환 군과의 비교를 통해 초고령층의 변별적 프로파일을 제시해야 할 것이다. 예를 들어, 실어증, $\mathrm{MCI}, \mathrm{AD}$ 와 초고령층의 수행 프로파 일을 인지-의사소통의 과제별로 비교할 수 있다. 넷째, 의사소통 의 인지적 예측변인을 보완할 필요성이 제기된다. 본 결과에서 집단 I의 단어정의 및 담화, 집단 II의 단어유창성, 화용 표현 등 에 대한 인지적 예측변인을 추가해야 할 것이다.

중심 단어 : 초고령층, 인지-의사소통, 수행 프로파일, 중재.

\section{Ethical Statement \\ N/A}

\section{Acknowledgments \\ N/A}

\section{Declaration of Conflicting Interests}

There is no conflict of interests.

\section{Funding}

This work was supported by the Ministry of Education of the Republic of Korea and the National Research Foundation of Korea (NRF-2020 S1A5A8040953).

\section{ORCIDiD}

Mi Sook Lee

https://orcid.org/0000-0001-9255-565X 


\section{REFERENCES}

Amariglio, R. E., Becker, J. A., Carmasin, J., Wadsworth, L. P., Lorius, N., Sullivan, C., et al. (2012). Subjective cognitive complaints and amyloid burden in cognitively normal older individuals. Neuropsychologia, 50(12), 2880-2886.

Bakos, D. S., Couto, M. C. P. D. P., Melo, W. V., Parente, M. A. D. M., Koller, S. H., \& Bizarro, L. (2008). Executive functions in the young elderly and oldest old: A preliminary comparison emphasizing decision making. Psychology and Neuroscience, 1(2), 183-189.

Burton, C. L., Strauss, E., Hultsch, D. F., \& Hunter, M. A. (2009). The relationship between everyday problem solving and inconsistency in reaction time in older adults. Aging, Neuropsychology, and Cognition,16(5), 607-632.

Fukuda, K. \& Vogel, E. K. (2009). Human variation in overriding attentional capture. Journal of Neuroscience, 29(27), 8726-8733.

Hagberg, B., Bauer Alfredson, B., Poon, L. W., \& Homma, A. (2001). Cognitive functioning in centenarians: A coordinated analysis of results from three countries. The Journals of Gerontology: Series B, 56(3), 141-151.

Kang, Y. (2006). A normative study of the Korean Mini-Mental State Examination (K-MMSE) in the elderly. Korean Journal of Psychology, 25(2), 1-12.

Keller-Cohen, D., Fiori, K., Toler, A., \& Bybee, D. (2006). Social relations, language and cognition in the 'oldest old'. Ageing and Society, 26(4), 585-605.

Kim, B. S. \& Lee, M. S. (2019). Comparison of coherence and efficiency in discourse production of middle-old and old-old elderly. Audiology and Speech Research, 15(1), 63-70.

Kim, B. S., Lee, M. S., Kim, H., Kim, B. S., Lee, M. S., \& Kim, H. (2015). Subjective language complaints: Are they reflected in objective language test performance? Communication Sciences and Disorders, 20(2), 214-221.

Kim, H. \& Kim, S. R. (2013). Development of short form of the Korean version-the Boston Naming Test (K-BNT-15) based on item response theory. The Journal of the Korea Contents Association, 13(12), 321-327.

Kim, H. \& Na, D. L. (2012). Paradise Korea-Western Aphasia Battery (Revised). (2nd ed.). Seoul: Paradise Welfare Foundation.

Klencklen, G., Lavenex, P. B., Brandner, C., \& Lavenex, P. (2017). Working memory decline in normal aging: Memory load and representational demands affect performance. Learning and Motivation, 60, 10-22.

Lee, M. S. (2013). Development and application of cognitive-pragmatic language ability assessment protocol for traumatic brain injury (CAPTBI) (Doctoral dissertation). Seoul: Yonsei University.

Lee, M. S. (2015). Meta-analysis of correlation between subjective and objective cognitive-linguistic tests: Focused on normal aging, MCI, and dementia. Journal of the Korea Academia-Industrial Cooperation Society, 16(11), 7414-7423.

Lee, M. S. (2021). Aging and Cognitive-communication Disorders. (1st ed.), (pp.3-88). Paju: Koonja Publishing.

Lee, M. S. \& Kim, B. S. (2018). Correlation between figurative language and cognitive-linguistic ability in older adults by age. Journal of Special Education and Rehabilitation Science, 57(4), 115-137.

Lee, M. S. \& Kim, B. S. (2020). Transfer effects of working memory intervention on linguistic abilities in patients with dementia. Audiology and Speech Research, 16(1), 58-69.
Lee, M. S. \& Kim, B. S. (2021). Informant-report scale on cognitivelinguistic abilities of the elderly (ISCOLE): Focused on the reliability, validity, and correlation with objective test. Journal of Special Education and Rehabilitation Science, 60(1), 265-288.

Lee, M. S., Kim, B. S., \& Lim, J. S. (2020). Reliability and validity of the Brief Test of Cognitive-Communication Disorders. Communication Sciences and Disorders, 25(4), 872-889.

MacDonald, S. W., Hultsch, D. F., \& Dixon, R. A. (2011). Aging and the shape of cognitive change before death: Terminal decline or terminal drop? The Journals of Gerontology: Series B, 66(3), 292-301.

MacPherson, S. E., Phillips, L. H., \& Della Sala, S. (2002). Age, executive function, and social decision making: A dorsolateral prefrontal theory of cognitive aging. Psychology and Aging, 17(4), 598-609.

Marini, A., Boewe, A., Caltagirone, C., \& Carlomagno, S. (2005). Agerelated differences in the production of textual descriptions. Journal of Psycholinguistic Research, 34(5), 439-463.

Maseda, A., Lodeiro-Fernández, L., Lorenzo-López, L., Núñez-Naveira, L., Balo, A., \& Millán-Calenti, J. C. (2014). Verbal fluency, naming and verbal comprehension: Three aspects of language as predictors of cognitive impairment. Aging and Mental Health, 18(8), 10371045.

Matysiak, O., Kroemeke, A., \& Brzezicka, A. (2019). Working memory capacity as a predictor of cognitive training efficacy in the elderly population. Frontiers in Aging Neuroscience, 11, 126.

Melikyan, Z. A., Corrada, M. M., Dick, M. B., Whittle, C., PaganiniHill, A., \& Kawas, C. H. (2019). Neuropsychological test norms in cognitively intact oldest-old. Journal of the International Neuropsychological Society, 25(5), 530-545.

Miller, L. S., Mitchell, M. B., Woodard, J. L., Davey, A., Martin, P., Poon, L. W., et al. (2010). Cognitive performance in centenarians and the oldest old: Norms from the Georgia centenarian study. Neuropsychology, development, and cognition. Section B, Aging, Neuropsychology and Cognition, 17(5), 575-590.

Montine, T. J., Cholerton, B. A., Corrada, M. M., Edland, S. D., Flanagan, M. E., Hemmy, L. S., et al. (2019). Concepts for brain aging: Resistance, resilience, reserve, and compensation. Alzheimer's Research and Therapy, 11(1), 22.

Park, M. S. \& Choi, J. Y. (2003). A normative study of the modified trail making test for elderly Korean people. Korean Journal of Clinical Psychology, 22(1), 247-259.

Peach, R. K. \& Shapiro, L. P. (2020). Cognition and Acquired Language Disorders: An Information Processing Approach. (1st ed., M. S. Lee \& S. R. Kim, Trans.). Maryland Heights, MO: Elsevier-Health Sciences Division.

Poon, L. W., Jazwinski, M., Green, R. C., Woodard, J. L., Martin, P., Rodgers, W. L., et al. (2007). Methodological considerations in studying centenarians: Lessons learned from the Georgia centenarian studies. Annual Review of Gerontology and Geriatrics, 27(1), 231-264.

Rey-Mermet, A. \& Gade, M. (2018). Inhibition in aging: What is preserved? What declines? A meta-analysis. Psychonomic Bulletin and Review, 25(5), 1695-1716.

Salthouse, T. A. (2000). Item analyses of age relations on reasoning tests. Psychology and Aging, 15(1), 3-8.

Seniów, J., Litwin, M., \& Leśniak, M. (2009). The relationship between non-linguistic cognitive deficits and language recovery in patients with aphasia. Journal of the Neurological Science, 283(1-2), 91-94.

Thompson, T. W., Waskom, M. L., Garel, K. L., Cardenas-Iniguez, C., Reynolds, G. O., Winter, R., et al. (2013). Failure of working 
memory training to enhance cognition or intelligence. PLoS One, 8(5), e63614.

Unsworth, N., Spillers, G. J., \& Brewer, G. A. (2012). The role of working memory capacity in autobiographical retrieval: Individual differences in strategic search. Memory, 20(2), 167-176.

Verhaeghen, P. (2011). Cognitive processes and ageing. In StuartHamilton, I. (1st ed.). Introduction to Gerontology (pp.1-20). Cambridge: Cambridge University Press.

Wahl, H. W., Schmitt, M., Danner, D., \& Coppin, A. (2010). Is the emergence of functional ability decline in early old age related to change in speed of cognitive processing and also to change in personality? Journal of Aging and Health, 22(6), 691-712.

Wasylyshyn, C., Verhaeghen, P., \& Sliwinski, M. J. (2011). Aging and task switching: A meta-analysis. Psychology and Aging, 26(1), 15-20.

Whittle, C., Corrada, M. M., Dick, M., Ziegler, R., Kahle-Wrobleski, K., Paganini-Hill, A., et al. (2007). Neuropsychological data in nondemented oldest old: The 90+ study. Journal of Clinical and Experimental Neuropsychology, 29(3), 290-299.

Yeom, T., Park, Y., Oh, K., Kim, J., \& Lee, Y. (1992). A Manual for K-WAIS. (2nd ed.), (pp.1-20). Seoul: Korea Psychology. 